\title{
Anomalous crustal structure beneath the Bay of Bengal and passive oceanic sedimentary basins
}

\author{
JAMES .N BRUNE and KEITH PRIESTLEY \\ Seismological Laboratory, Department of Geological Sciences, Mackay School of Mines, \\ University of Reno, Reno, Nevada 89557, USA
}

\begin{abstract}
Recently Brune and Singh (1986) reported evidence for anomalous continent-like crustal structure beneath the Bay of Bengal, possibly caused by perturbation in the temperature-pressure regime and consequent phase chage, partial melting, or mass transport (e.g. convection or underplating). Recent refraction results indicate the existence of an anomalous lower crustal or subcrustal layer of $P$-wave velocity about $7.3 \mathrm{~km}$ per second along the eastern North America passive margin, possibly a result of underplating of the oceanic crust just after initial rifting. We have searched for other evidence of anomalous crustal structure. The data suggest some mechanism may cause a general increase in the anomalous thickness of the crust with increasing thickness of the accumulated sediments, up to a thickness of about $6-7 \mathrm{~km}$. On the other hand, anamolous crustal structure may in fact be transitional between oceanic and continental, or may have been modified by aseismic ridges, thus requiring no sediment related structure modification mechanism. The explanation for all the data may require more than one mechanism, all probably involving severe temperature perturbations. The general tendency is for perturbations of normal oceanic crust to make it more continent-like, suggesting that normal oceanic crust is an unstable end-member in crustal states.
\end{abstract}

Keywords. Anomalous crust; underplating; Bay of Bengal; sedimentary basin.

\section{Introduction}

Recently Brune and Singh (1986) reported evidence for anomalous continent-like crustal structure beneath the Bay of Bengal. Surface wave dispersion data could not be fit by a simple model of oceanic crust with overlying sediments - the model expected from current understanding of the tectonic evolution of the Bay of Bengal (Curray et al 1982; Royer et al this volume). The data required a progressively more continent-like crustal structure as the sediment load increased northward. This suggested that either the sediment deposition had altered the crustal structure, or that the structure had not been a simple oceanic type before deposition. If the anomalous structure were a result of modification by the sedimentary load it might be caused by the perturbation in the temperature-pressure regime and consequent phase change, partial melting or mass transport (e.g. convection or underplating), and this might have important implications not only for the Bay of Bengal, but also for the classical geodynamic problem of basin formation.

Recent results of Trehu et al (1988) have increased interest in the problem. Using ocean bottom seismometers they were able to show the existence of an anomalous lower crustal or subcrustal layer of $P$-wave velocity about $7.3 \mathrm{~km}$ per second. They suggested that this could be the result of underplating of the oceanic crust just after the initial rifting of the North American plate from the African Plate. These results are discussed in more detail below. 
The existence of an anomalous crustal structure under a thick sedimentary basin on what might have been expectèd to be normal oceanic crust is so similar to the results for the Bay of Bengal that it suggests a common causal factor. The fact that for the Bay of Bengal the perturbation in structure correlates with sediment thickness (increasing from south to north) suggests that some sediment load effect should be considered for the Carolina Trough results. On the other hand, whatever mechanism is established for the Carolina Trough results should be considered as a possible explanation for the Bay of Bengal results.

If the original structure beneath the Bay of Bengal was not oceanic, then some modifications of the current plate tectonic model for the Indian Ocean might be suggested. However the excellent fit between the coast of India and the coast of Antarctica (Lawver and Scotese 1987) argues against any other structure than pure oceanic in the majority of the Bay of Bengal.

An alternate explanation of the anomalous dispersion might be a combination of structural perturbations, including effects of a marginal rifting event, and perturbations by the $90 \mathrm{deg}$ east ridge and the $85 \mathrm{deg}$ east ridge (e.g. through underplating).

\section{Evidence from other areas}

Brune and Singh (1986) mentioned evidence that anomalous structure underlying thick sediments on oceanic structure might not be unique to the Bay of Bengal, i.e. some anomalous surface wave dispersion evident in figure 8 of Sykes and Oliver-Part II (1964) for the Argentine sedimentary basin. We have searched for other evidence of the phenomenon, and report the results here. Most of the evidence is from published studies. A paper documenting anomalous crustal structure in small ocean basins was published by Menard (1967). Although his results may be related to the data considered here, we have not placed heavy emphasis on it because in most cases it is not clear that the original structure before sedimentation was oceanic.

We have not included results from active tectonic areas such as the Bering Sea, the Mediterranean, and the Sea of Okotsk, which, although they have considerable thicknesses of sediments, have not been stable tectonically in the same manner as passive margins and the Bay of Bengal, and in some cases seem to have normal oceanic crust underlying the sediments, possibly a result of creation of new crust by back-arc spreading or some other type of active tectonism.

\section{Data}

Selected data correlating the sediment thickness to the thickness of the anomalous crust is plotted in figure 1 , and is discussed below.

\subsection{The Bengal Fan}

The data for the Bengal Fan are taken from Brune and Singh (1986). For a discussion of that data the reader is referred to the publication. The main conclusion from the data is that there is an apparent correlation between sediment thickness and thickness 


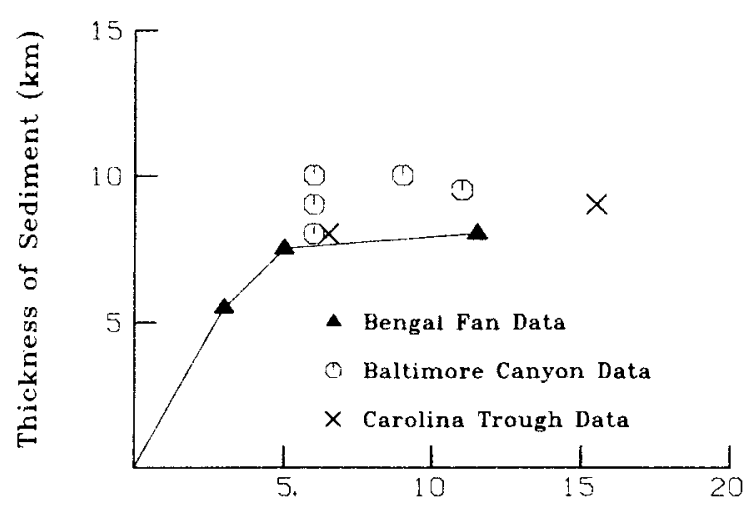

Thickness of Anomalous (excess) Crust (km)

Figure 1. Plot of selected data for thickness of sediments versus thickness of anomalous crust, i.e. crustal thickness in excess of $6 \mathrm{~km}$.

of anomalous lower crust (figure 1). This apparent correlation suggests that some causal mechanism increases in effect from south to north, rather than parallel to the coast as might be expected from a remanent continental margin effect or the initial rifting event or from effects of the 85 East and 90 East ridges. However since the width of the Bay of Bengal decreases from south to north it would take less of a contaminating structure to influence the apparent average crustal thickness.

\subsection{The Arabian Sea}

Singh (1988) has recently published results on surface wave dispersion across the Arabian Sea. The Indus Fan sedimentary basin in not as large as the Bengal Fan and the location of seismic stations and earthquake sources is not as favourable, with no good paths crossing the thick part of the fan. Many of the paths are contaminated by the Maldive and Laccadive ridges. The dispersion results suggest the existence of anomalous crust for much of the Arabian Sea area studied by Singh (1988).

\subsection{Anomalous crustal structure at passive continental margins}

Recently Trehu et al (submitted 1989) reported new results for the crustal structure underlying the sedimentary basin of the Carolina trough. These results were obtained using new ocean bottom seismographs which recorded clear deep crust and mantle arrivals, arrivals not reliably recorded in earlier studies using surface sonobouys. The data provided evidence for a thick (up to $15 \mathrm{~km}$ ) high-velocity $(7.2-7.6 \mathrm{~km} / \mathrm{s}$ ) lower crustal or upper mantle layer extending beneath the Carolina trough and the adjacent ocean basin. This layer was either very thin or absent landward of the hinge zone (continental broader). Trehu et al, following similar results from the Baltimore Canyon Trough (LASE Study Group 1986), interpreted this anomalous crust to represent material that was underplated to the crust during the late stage of continental drifting and early seafloor spreading.

Both the Carolina Trough and The Baltimore Canyon have very thick sedimentary accumulations, similar to the thicknesses of sediments in the Bengal Fan, and thus fit 
the correlation of anomalous crust with sediment thickness. However results from the Hatton Bank, a sediment starved margin, also indicate the presence of an anomalous layer which Trehu et al (1989) label as "underplated", but it is more localized under the continental border.

\subsection{Gravity}

A detailed study of gravity using data collected in recent cruises has not been carried out in the Bay of Bengal. Liu et al (1982) presented a free-air gravity map of the Bengal Fan. The free-air anomalies tend to be 20 to 30 milligals negative over the western part, and near zero close to the eastern margin near the Ninety-East Ridge. If massive sediments were flooded onto a perfectly rigid oceanic crust-mantle system the free air anomaly would be positive since more dense sediments would replace less dense water. However in a non-rigid system isostatic compensation will cause the anomaly to move more or less rapidly toward zero. Liu et al (1982) showed that the effect of flooding sediments around a ridge, in this case the buried Eighty-Five East ridge, is to create a local gravity low over the ridge, but we know of no mechanism which would give a broad low over a region where turbidity currents are rapidly depositing sediments. The negative values are probably related to more global factors, e.g. the assumed shape of the geoid. We do not believe that at this stage gravity provides a reliable constraint on the crust-mantle structure, or on the interpretation of the surface wave data.

Rao and Rao (1986) made an approximate gravity interpretation assuming two sedimentary layers of density 2.3 and $2.5 \mathrm{~g} / \mathrm{cc}$, respectively, and a basement density of $2.84 \mathrm{~g} / \mathrm{cc}$ overlying a mantle with density $3.4 \mathrm{~g} / \mathrm{cc}$. Their interpretation indicated a slight crustal thinning northward in the Bay of Bengal; however the interpretation depends on unverified density contrasts, does not consider a possible lower crustal layer, and does not deal with the question of local and regional compensation and thus cannot resolve the questions being dealt with in this paper.

\section{Discussion}

Figure 1 is a plot of sediment thickness versus thickness of the anomalous crustal layer (crustal thickness remaining after subtracting out a "normal" crustal thickness of $6 \mathrm{~km}$ ). The Bengal Fan data are connected by a line, starting at the origin (origin means no sediments and no excess crustal thickness). The data are consistent with some mechanism causing a general increase in the thickness of the crust with increasing thick ness of the accumulated sediments, but there is considerable scatter in the data and the correlation does not establish any particular mechanism to explain the data. If there is a causal mechanism relating anomalous crustal thickness to sediment thickness, figure 1 suggests that it is not linear but has a "corner" at a sediment thickness of about $6-7 \mathrm{~km}$, possibly suggesting a saturation effect so that beyond this thickness, further sediments have less of an effect in modifying the structure.

Possible general interpretations of the data include:

(i) The presence of a thick layer of sediments over normal oceanic crust for long periods of geologic time leads to modification of the underlying crust-mantle structure 
by a mechanism yet to be established e.g. thermal blanketing, phase change, underplating; etc. (causal sedimentary effect).

(ii) Since all the data are from oceanic areas near continental margins, or areas with aseismic ridges, the actual underlying crust may not have been (before sedimentation) originally normal oceanic as assumed, but in fact transitional between oceanic and continental, or may have been modified by aseismic ridges, and thus no sediment related structure modification mechanism is required.

There is no established mechanism for a causal connection between sediment load and crustal thickness. The data suggest that the modification in structure occurs near the Moho, but there is strong evidence from our recently developed understanding of the evolution of oceanic crust that the oceanic Moho is a compositional boundary, not a phase change or pressure-temperature boundary. Thus it is difficult to see how sediment load could lead to large structural changes near the Moho. Furthermore the most obvious candidate for a pressure effect, the basalt-eclogite phase change would work the opposite direction and cause the Moho to shallow. This suggests that if there is a large structure modification near the Moho, it must involve either temperature or mass transport, or both. One such mechanism might be reactivated basalt underplating brought about by an increased geothermal gradient, possibly from the sedimentary blanketing effect and/or reactivated shallow convection in the mantle. Neither of these mechanisms has been quantitatively evaluated.

Since great sedimentary basins are of necessity near continents (to provide a supply of sediment), there is usually some question as to where the exact continent-ocean boundary is, and whether or not the structure of the crust underneath the basin is truly oceanic. An exact knowledge of plate tectonic history may be required to establish the original type of structure unambiguously. In the case of the Bengal Fan the location of the remnant boundary between the Antarctic and Indian plates is well established from the deflection of the vertical data (Royer et al this volume), and the most recent plate reconstructions (Lawver and Scotese 1987), and thus we expect the Bengal Fan to be underlain by oceanic crust.

Even if it is accepted that the Bay of Bengal is underlain by oceanic crust, there is the possibility of structural perturbations not only by continental margin effects but also by anomalous structures such as aseismic oceanic ridges. The nature of the Ninety-East Ridge is not known for certain, and conceivably could exert some influence on the surrounding structure. The same is true for the buried Eighty-Five Degree East Ridge.

\section{Conclusion}

Evidence for anomalously thick crust in areas expected from plate tectonic reconstructions to have normal oceanic crust suggest that various factors may be acting to perturb the crust-mantle structure. Evidence from the Bay of Bengal suggests a strong correlation with sediment thickness. Evidence from eastern U.S. passive continental margin sedimentary basins suggests a similar anomalous crustal structure related to the original rifting event. If there is a strong effect related to sediment blanketing it could result from temperature perturbations and related mass transport phenomena, e.g. underplating. The explanation for all the data may require more than one mechanism, e.g. mechanical mechanisms related to stretching and rifting, 
mechanisms related to thermal effects of sedimentary blanketing, and mechanisms related to emplacement of aseismic ridges. All of these probably involve severe temperature perturbations. Whatever mechanisms are operating, the general tendency for perturbations of normal oceanic crust is to alter the structure in such a way as to make it more continent-like. Perhaps this indicates that normal oceanic crust is an unstable initial crustal state, and varinus mechanisms can restructure it toward a more continental structure.

\section{References}

Brune J N and Singh D D 1986 Continent-like crustal thickness beneath the Bay of Bengal sediments; Bull. Seismol. Soc. Am. 76 191-203

Curray J R, Emmel F J, Moore D G and Raitt R W 1982 Structure, tectonics, and geological history of the northeastern Indian Ocean. In The Oceans basins and margins (eds) Alan E M Nairn and Francis $G$ Stehli (Plenum Publishing Corporation) Vol. 6

Lase Study Group 1986 Deep structure of the U.S. East Coast passive margin from large aperture seismic experiments (LASE); Mar. Petrol. Geol, 3 234-242

Lawver L A and Scotese C R 1987 In Gondwana six, structure, tectonics and geophysics (ed) G D McKenzie AGU Geophys. Monograph, Vol. 40 pp. 17-23

Liu C S, Sandwell D T and Curray J R 1982 The negative gravity field over the 85 E ridge; J. Geophys. Res. $877673-7686$

Menard H W 1967 Transitional types of crust under small ocean basins; J. Geophys. Res. 72

Rao T C S and Rao B B 1985 Some structural features of the Bay of Bengal; Tectonophysics 124 141-153

Royer J-Y, Sclater J G and Sandwell D T 1989 Proc. Indian Acad. Sci. (Earth Planet. Sci.) 98 7-24

Singh D D 1988 Quasi-continental oceanic structure beneath the Arabian fan sediments from observed surface-wave dispersion studies; Bull. Seismol. Soc. Am. 78 1510-1521

Sykes $L R$ and Oliver $J 1964$ The propagation of short-period seismic surface waves across oceanic areas-Part I and Part II; Bull. Seismol. Soc. Am. 54 1341-1416

Trehu A M, Klitgord K D, Sawyer D S and Buffler R T The geophysical framework of the Continental United States (eds) L Pakiser and W D Mooney (GSA memoir) 